\title{
The Impact of Meteorological Factors on Fine Particulate Pollution in Northeast China
}

\author{
Can Meng ${ }^{1,2}$, Tianhai Cheng ${ }^{*}$, Fangwen Bao ${ }^{3}$, Xingfa Gu${ }^{1}$, Jian Wang ${ }^{4}$, Xin Zuo ${ }^{1,2}$, \\ Shuaiyi Shi ${ }^{{ }^{*}}$
}

\author{
${ }^{1}$ State Key Laboratory of Remote Sensing Science, Aerospace Information Research Institute, Chinese Academy of \\ Sciences, Beijing 100094, China \\ ${ }^{2}$ University of Chinese Academy of Sciences, Beijing 100049, China \\ ${ }^{3}$ Department of Ocean Sciences and Engineering, Southern University of Science and Technology, Shenzhen 518055, \\ China \\ ${ }^{4}$ Department of Geography, The Ohio State University, Columbus, OH 43210, USA
}

\begin{abstract}
Due to biomass burning and coal combustion, heavy fine particulate matter $\left(\mathrm{PM}_{2.5}\right)$ pollution frequently occurs in Northeast China, threatening the health of more than 117 million inhabitants. Although meteorological conditions have always been considered key factors in the accumulation and dilution of $\mathrm{PM}_{2.5}$ pollution, their exact contribution to particulate pollution in Northeast China is still highly uncertain. Applying multiple regression analysis to observational data, we identify the wind speed, temperature inversion, and height of the planetary boundary layer as the dominant meteorological factors affecting $\mathrm{PM}_{2.5}$ pollution $\left(\mathrm{PM}_{2.5}>75 \mu \mathrm{g} \mathrm{m}^{-3}\right)$ in the major cities of Northeast China, with the wind speed and the planetary boundary layer playing the primary roles in Harbin and Shenyang, and Changchun, respectively. Heavy pollution $\left(\mathrm{PM}_{2.5}>\right.$ $150 \mu \mathrm{g} \mathrm{m}^{-3}$ ) in this region typically occurs when the wind speed is less than 20 knots, the planetary boundary layer is below $500 \mathrm{~m}$, and the temperature inversion is greater than $6^{\circ} \mathrm{C}$. These results suggest that reducing the $\mathrm{PM}_{2.5}$ pollution requires us to focus not only on anthropogenic emissions but also on special meteorological conditions that can affect the air pollution mechanisms in Northeast China.
\end{abstract}

Keywords: Fine particulate $\left(\mathrm{PM}_{2.5}\right)$ pollution; Multiple regression method; Wind speed; Temperature inversion; Planetary boundary layer height.

\section{INTRODUCTION}

Several extremely severe atmospheric haze events have occurred recently in Northeast China, a major crop straw burning region of China, with air pollution reaching up to nearly 2-3 times of the historical record (Chen et al., 2015; Wen et al., 2018). Fine particulate matter $\left(\mathrm{PM}_{2.5}\right)$ has been proved harmful to human health and regarded as the main factor impairing visibility (He et al., 2001; Wang and Christopher, 2003; Jung et al., 2010; Heal et al., 2012; Kan et al., 2012). It exerts large influences on the development of planetary boundary layer (PBL) through the positive feedback loop between aerosol and PBL (Petäjä et al., 2016; Li et al., 2017b; Lou et al., 2019) which in turn deteriorates the air quality. Besides, aerosol tends to affect the formation

\footnotetext{
* Corresponding author.

E-mail address: shisy01 @radi.ac.cn (S. Shi); chength@radi.ac.cn (T. Cheng)
}

and development of cloud and precipitation through directly altering the radiation reaching the ground surface (Lohmann and Feichter, 2001; Yang et al., 2016) or indirectly altering the structure of clouds by acting as cloud condensation nucleus (Twomey, 1977; Chen et al., 2016; Guo et al., 2016; Guo et al., 2019), albeit its inconclusive effect on weather and climate systems (Rosenfeld et al., 2014; Fan et al., 2016; Li et al., 2019). In view of its potential huge influence, fine particulate pollution has attracted great attention from the Chinese government. Many regulations and standards have been made to control the fine particulate pollution (Wen et al., 2018). By adopting these measures, a gradual decrease in the $\mathrm{PM}_{2.5}$ concentration over time has been witnessed recently (Wen et al., 2018). However, $\mathrm{PM}_{2.5}$ pollution in Northeast China is still non-negligible, especially around harvest time (Chen et al., 2017).

The pollution during the heating season in Northeast China is mainly caused by evening biomass burning and coal combustion (Fang et al., 2001; Zhang et al., 2011; Fang et al., 2017). In addition, meteorological factors are important to the variation of $\mathrm{PM}_{2.5}$ concentrations. Researches show 
that wind speed has a negative effect on $\mathrm{PM}_{2.5}$ concentration (Chen et al., 2015; Liang et al., 2015; Chen et al., 2017; Wen et al., 2018). Wind speed can facilitate plume spread and dilution, leading to lower $\mathrm{PM}_{2.5}$ concentrations. In such way, atmospheric horizontal mixing has been considered as one of the most efficient dilution mechanisms (Marcazzan et al., 2001). Studies show that lower height of the planetary boundary layer (HPBL) weakens the dispersion ability of the atmosphere (Seinfeld et al., 1998; Dickerson et al., 2007; Marcazzan et al., 2001; Zhang et al., 2015; Wen et al., 2018). HPBL, also known as the boundary layer top, refers to the thickness of the planetary boundary layer. The characteristic of the boundary layer height is that the turbulence coefficient at this height is zero and the free atmosphere is above it. The diffusion and transportation of pollutants in the lower atmosphere depends to a large extent on the boundary layer structure. Within the boundary layer, turbulence can fully mix particles and gases (Garratt, 1994). In addition, the inversion layer boosts the accumulation of pollutants in the atmosphere (Wang et al., 2014b; Fang et al., 2017). Temperature inversion is a reversal of the normal behavior of temperature in the troposphere, in which a layer of cool air at the surface is overlain by a layer of warmer air. When inversion occurs, upward movement of the lower atmosphere decreases and the pollutants are trapped in the lower atmosphere (Xu et al., 2019). In winter, the recurrent or continuous thermal inversions with fog at ground level are the major contributors to the massive amount of air pollutants accumulated in the lower layer of the atmosphere (Marcazzan et al., 2001). Moreover, haze weather can form in a faster way under high humidity conditions. Some researchers conclude that the relative humidity $(\mathrm{RH})$ could well explain the daily variations of $\mathrm{PM}_{2.5}$ (Sun et al., 2013; Fang et al., 2017; Ma et al., 2017). Previous studies indicated that the synoptic scale meteorological conditions and multiple meteorological factors can have a complicated impact to the $\mathrm{PM}_{2.5}$ pollution (Chen et al., 2018; Liu et al., 2018; Miao et al., 2017; Wang et al., 2014a).

Three typical large cities of Northeast China (i.e., Harbin, Changchun, and Shenyang) were studied in this research, using statistical data and regression model analysis, to investigate the impact of different meteorological factors on major cities in Northeast China. The study result of this research is of great benefit to making suitable and effective strategies for $\mathrm{PM}_{2.5}$ control in Northeast China.

\section{DATA AND METHODS}

\section{Study Area}

As shown in Fig. 1, Northeast China is covered mostly by plain. The Northeast Plain is surrounded by mountains, alluvial plains and terraces, with an elevation of about $200 \mathrm{~m}$. The Northeast Plain is located in a temperate and warm temperate zone with continental monsoon climate characteristics. Significant seasonal differences exist in this area. The summer is short, warm and rainy. Meanwhile the winter is long, cold, and snowy. And the monsoon alternates between winter and summer.

Considering their meteorological conditions and urban development status, three typical large cities in Northeast
China were selected in this study to reflect the major characteristics of $\mathrm{PM}_{2.5}$ pollution in Northeast China. Among the three cities, Harbin, the capital of Heilongjiang Province, is located in the highest latitude area, having the lowest temperature, with a flat terrain. Over 10.9 million people live in Harbin. The southeastern part of Harbin is located in the hills; meanwhile, mountainous area occupied the north part. The Songhua River flows through the middle part of Harbin. Changchun is located in the middle part of Northeast China with over 7.5 million people. The Changchun area, apart from a small area of low hills in the east, is mostly comprised of terraces. The terrain of Changchun is flat and convenient for transportation (Fang et al., 2001). In Changchun, from November to March, coal burning phenomenon for heating purpose is widespread. The heating area is scattered in onefourth of the city area (Fang et al., 2001). Shenyang, the largest city in Northeast China, has over 8.3 million people (Xu et al., 2000; Han et al., 2010). It is located in the southeastern part of Northeast China, mainly in the plains, with mountains and hills concentrated in the southeast. Shenyang shows similar meteorological characteristics with the other two cities mentioned above: a monsoon-influenced humid continental climate, which has monsoon-caused hot, humid summers and dry, cold winters driven by the Siberian anticyclone (Han et al., 2010).

\section{Data Source and Treatment}

The time period of the studied $\mathrm{PM}_{2.5}$ data ranges from 2015 to 2017, provided by the China Meteorological Administration. The continuous hourly $\mathrm{PM}_{2.5}$ concentration data has been monitored by the 33 stations: 12 sites in Harbin, 10 sites in Changchun, and 11 sites in Shenyang. As can be seen in Fig. 1, the sites are evenly distributed throughout the cities. Thus the hourly average value of these sites can reasonably represent the $\mathrm{PM}_{2.5}$ concentration of the three cities. To keep consistency with the meteorological data, the $\mathrm{PM}_{2.5}$ concentration was calculated at 08:00 and 20:00 local time. The $\mathrm{PM}_{2.5}$ data is classified into three states: the non-pollution state $\left(\mathrm{PM}_{2.5} \leq 75 \mu \mathrm{g} \mathrm{m}^{-3}\right)$, pollution state $\left(\mathrm{PM}_{2.5}>75 \mu \mathrm{g} \mathrm{m}^{-3}\right)$, and heavy pollution state $\left(\mathrm{PM}_{2.5}\right.$ $>150 \mu \mathrm{g} \mathrm{m}^{-3}$ ) (Ma et al., 2017; Tian et al., 2017).

Meteorological data comes from the radiosonde measurements provided by the Integrated Global Radiosonde Archive developed by the American National Climatic Data Center (NCDC) (Durre et al., 2006). The humidity data and wind data are extracted specifically with wind velocity and wind direction at $850 \mathrm{hPa}$. In general, temperature drops as the altitude increases, beneficial to the convective phenomenon which accelerates the pollutants in the lower layer moving and diffusing upward. However, when temperature inversion occurs, the upward movement of the lower atmosphere is weakened, causing the accumulation of atmospheric pollutants in the lower layer. Temperature inversion phenomenon can be detected by the temperature profile of the atmosphere. Two factors, namely the temperature difference of the inversion layer $\left(T I \_T\right)$ and the depth of the inversion layer $\left(T I \_D\right)$, are used to describe the intensity of temperature inversion. In this research, the two factors of the inversion layer are derived from the Integrated Global Radiosonde 
(a) China

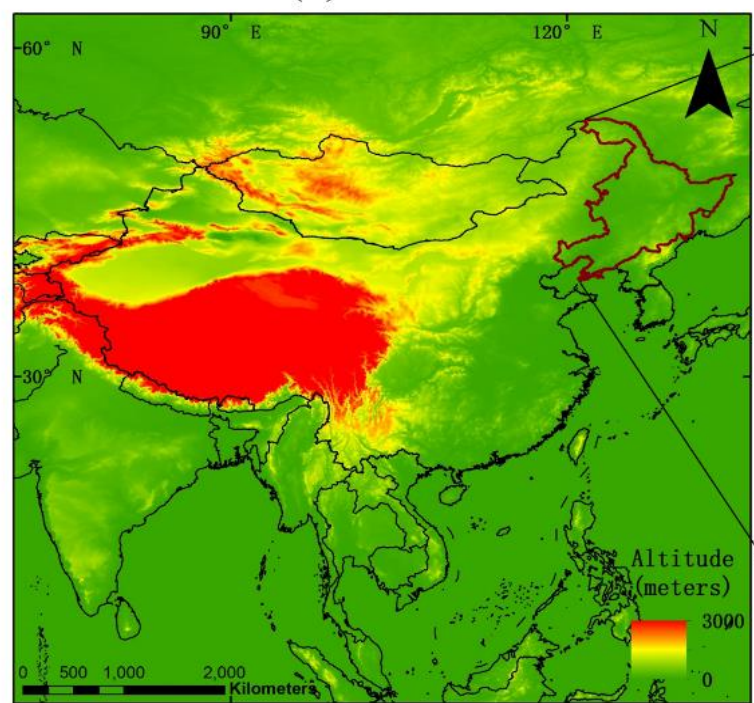

(c) Shenyang

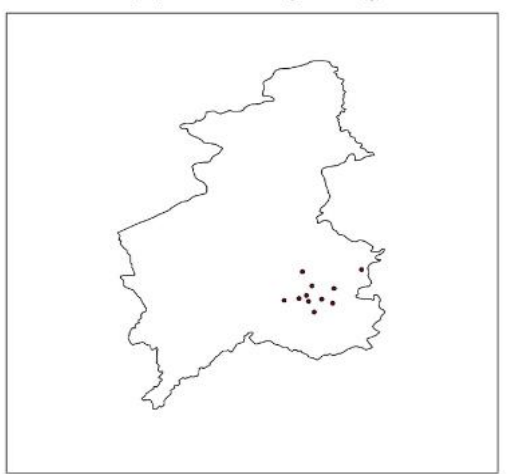

(d) Changchun

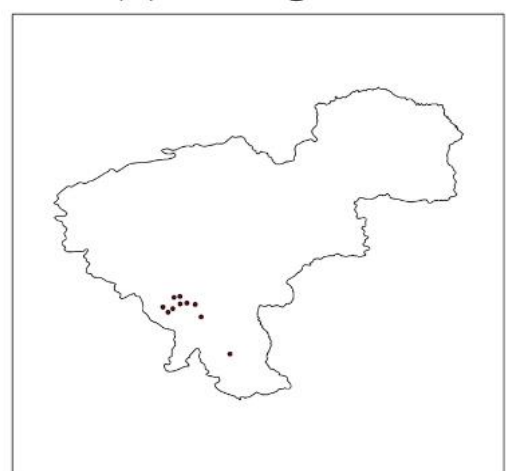

(b) Northeast China

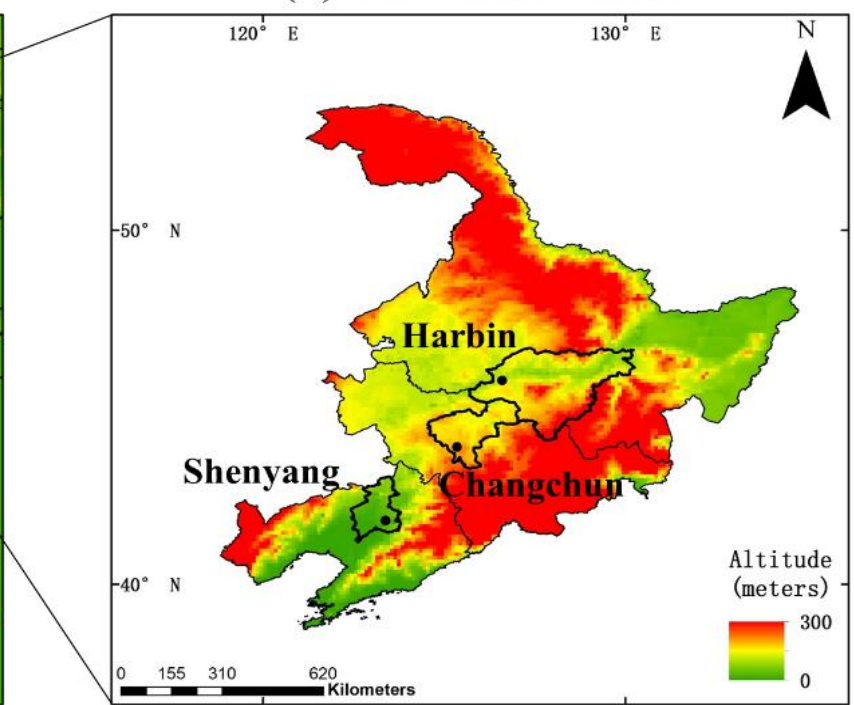

(e) Harbin

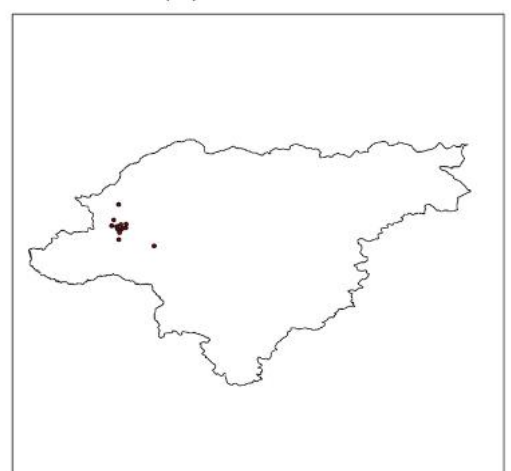

Fig. 1. Map of the study area: (a) the topographic map of China and the location of Northeast China; (b) the topographic map of Northeast China and the location of Shenyang, Changchun, and Harbin; and the location of $\mathrm{PM}_{2.5}$ studying sites in (c) Shenyang, (d) Changchun, and (e) Harbin.

Archive (IGRA) soundings data. We first analyze the temperature data for different air layers and find if there exists a temperature sequence segmentation in the profile that has monotonic increasing trend with the increase of the layer heights. If exist, the temperature inversion is defined. Then the temperature difference is calculated by subtracting the temperatures at the top and bottom of the inversion layers. And the depth of the inversion layer is calculated by subtracting the heights at the top and bottom of the inversion layers.

HPBL data used in this research is provided by National Centers for Environmental Prediction (NCEP) and Final (FNL) Reanalysis data. It is collected at 06:00 and 18:00 UTC. The HPBL data is a grid dataset and the horizontal resolution of HPBL is $1 \times 1^{\circ}$ (Zang et al., 2017). In this research, the HPBL values of Harbin, Changchun and Shenyang are calculated using the inverse distance weighting method based on the values in four closest grid points.

\section{Methods}

In order to decouple the contribution of different meteorological factors, a multiple regression model was used to analyze the correlations between $\mathrm{PM}_{2.5}$ concentration and meteorological factors. Based on atmospheric dispersion equations, the particulate concentration is correlated with meteorological parameters in multiplicative form other than additive form (Hien et al., 2002; Chaloulakou et al., 2003; $\mathrm{Gu}$ et al., 2018). The multiple regression analysis model can be constructed as follows:

$B=k \times f\left(\tau_{n}\right)$

where $\mathrm{B}$ represents the monitored $\mathrm{PM}_{2.5}$ concentration, $k$ represents autochthonic contribution to $\mathrm{PM}_{2.5} . k$ is considered to remain unchanged during each season. $f\left(\tau_{n}\right)$ represents the meteorological impact on $\mathrm{PM}_{2.5}$. Furthermore, the regression model can be expressed as follows:

$$
B=k \prod\left(P_{i}\right)^{\alpha_{i}}
$$

The exponent $\alpha_{i}$ represents the response of particulate concentration $\mathrm{B}$ to the rate of change in meteorological 
parameter Pi. $f\left(\tau_{n}\right)$ was calculated using five meteorological factors (Pi) in this model: wind velocity (WV), HPBL, TI_T, TI_D and RH. As a result, the model can be expressed as follows:

$$
B=k \times(W V)^{\alpha_{1}} \times(H P B L)^{\alpha_{2}} \times\left(T I \_T\right)^{\alpha_{3}} \times\left(T I \_D\right)^{\alpha_{4}} \times(R H)^{\alpha_{5}}
$$

Then, take the logarithm for both sides of this equation. Eq. (3) can be further transformed to a multiple linear regression model:

$\ln B=\ln k+\sum_{i} \alpha_{i} \ln \left(P_{i}\right)+\varepsilon$

where $\ln k, \alpha_{i}$ and $\varepsilon$ represent the intercept, regression coefficients, and the error term respectively. WV, RH, TI_T, TI_D, and HPBL were selected in this research as the studied meteorological parameters which influence the $\mathrm{PM}_{2.5}$ concentration characteristics in Northeast China. To find the determinant(s) of the $\mathrm{PM}_{2.5}$ concentrations among various indicators, the data were analyzed by a stepwise multiple regression method with a significance level of $95 \%$ $(p=0.05)$ set for the regression coefficients.

The regression coefficient $\alpha_{i}$ can only represent the positive or negative relationship between the $\mathrm{PM}_{2.5}$ concentration and the meteorological factors. To find the most important factors that impact the $\mathrm{PM}_{2.5}$ concentration in different cities of Northeast China, we calculated the standardized coefficient of the regression model. The standardized coefficient can compare the relative importance of different kind of factors to the $\mathrm{PM}_{2.5}$ concentration. The bigger the absolute value is, the more important the meteorological factor will be (Newman and Browner, 1991).

\section{RESULT AND DISCUSSION}

\section{Variation of the PM${ }_{2.5}$ Concentrations Correlated with Different Meteorological Factors}

Massive biomass burning and coal consumption together with meteorological conditions potentially cause the high level of $\mathrm{PM}_{2.5}$ pollution in Northeast China's winter (Han et al., 2010; Segura et al., 2013). Studies show that $\mathrm{PM}_{2.5}$ pollution in Northeast China originates from anthropogenic activities, such as straw burning and coal combustion for both industrial and domestic purpose (Zhang et al., 2010; Guan et al., 2018). Meanwhile, individual meteorological factors such as relative humidity, wind speed and temperature inversion have nonnegligible impacts on local $\mathrm{PM}_{2.5}$ concentrations (Cheng and Lam, 1998; Ruellan and Cachier, 2001; Wen et al., 2018). The distribution and variation of the source of pollution are usually stable during each season. However, the dilution and accumulation abilities impacted by the meteorological conditions can change significantly. Investigating the impacts of meteorological factors is beneficial to a better understanding of the variations of $\mathrm{PM}_{2.5}$ mass concentrations.

As shown in Fig. 2, the correlation between $\mathrm{PM}_{2.5}$ concentration, and wind direction and speed were similar in the three cities. $\mathrm{PM}_{2.5}$ concentration is negatively associated with wind speed (Chen et al., 2017; Wen et al., 2018). High $\mathrm{PM}_{2.5}$ concentration tends to appear in a low wind speed
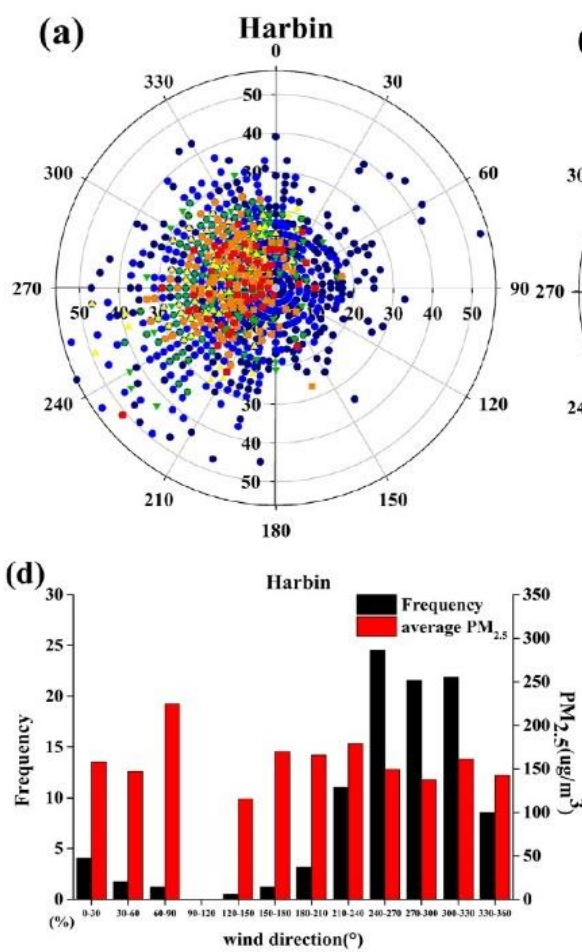
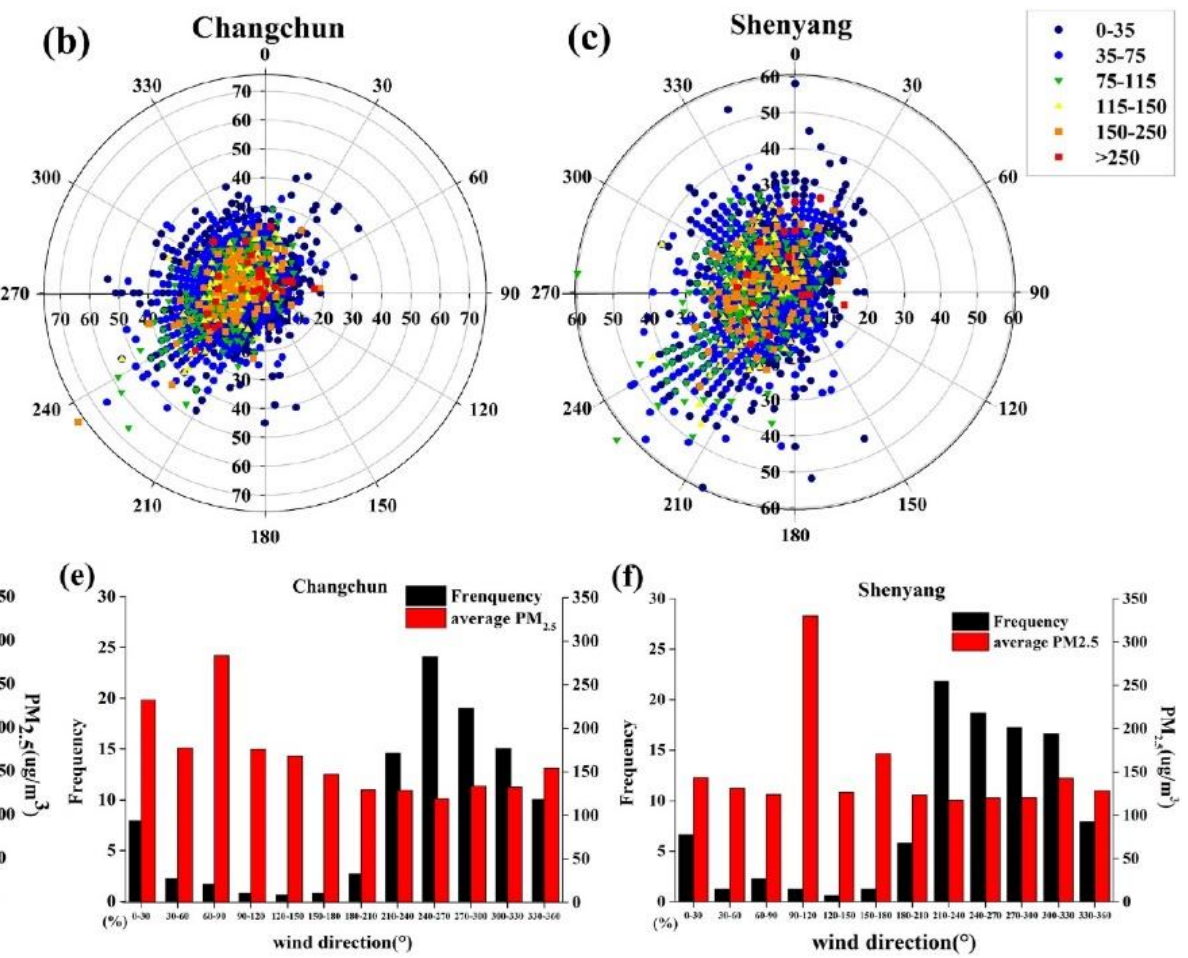

Fig. 2. Relationships between atmospheric pollutant concentrations, wind direction, and wind speed in (a) Harbin, (b) Changchun, and (c) Shenyang. Direction frequency and average $\mathrm{PM}_{2.5}$ concentrations in different direction during pollution days in (d) Harbin, (e) Changchun, and (f) Shenyang. 
situation. In Harbin, Changchun, and Shenyang, 79.2\%, 79.1\%, and $80.4 \%$ of the heavy $\mathrm{PM}_{2.5}$ pollution occurs in the days when the wind speed is less than 20 knots (a knot is a unit typically used to indicate wind speed, and thus used in this research; $1 \mathrm{knot}=1.852 \mathrm{~km} \mathrm{~h}^{-1}$ ). Biomass burning in spring and autumn and coal combustion for domestic heating in winter produce a great deal of air pollutants (Zhang et al., 2010; Bao et al., 2015). Higher wind speed is likely to promote the spread of pollutant, which is beneficial for the dilution of $\mathrm{PM}_{2.5}$ pollutants (Wen et al., 2018). The westerly wind prevails during pollution days in Northeast China. In Harbin, over $70 \%$ of pollution days $\left(\mathrm{PM}_{2.5}>75 \mu \mathrm{g} \mathrm{m}^{-3}\right)$ are related with the wind which has a direction between 240 $330^{\circ}$. As for Changchun and Shenyang, the dominant wind direction in pollution days is concentrated at $210-330^{\circ}$. In general, Harbin, Changchun, and Shenyang are mainly dominated by the southwest wind during the whole year; meanwhile the northwest wind is the prevailing wind in winter.

As shown in Fig. 3, in terms of statistics, there is a general negative correlation between HPBL and $\mathrm{PM}_{2.5}$ concentrations for Harbin, Changchun, and Shenyang. Heavy $\mathrm{PM}_{2.5}$ pollution usually occurs in the lower HPBL $(<500 \mathrm{~m})$. HPBL plays a vital role in the variation of $\mathrm{PM}_{2.5}$ concentration. The barrier effect at the top of the planetary boundary layer hinders air pollutants from being transported to the free troposphere, so that aerosol particles are constrained in the PBL (You et al., 2015; Li et al., 2017a;). Lower HPBL is usually related with higher concentrations of $\mathrm{PM}_{2.5}$, and higher HPBL is usually associated with smaller ground level $\mathrm{PM}_{2.5}$ concentration as a result of large vertical mixing ability (Yao et al., 2012).

As can be seen in Fig. 4, $\mathrm{PM}_{2.5}$ concentration is significantly and positively correlated with the intensity of temperature inversion which is described by TI_T and TI_D. In Harbin, Changchun, and Shenyang, 60.6\%, 44.8\%, and 56.9\% of $\mathrm{PM}_{2.5}$ pollution days occur with temperature inversion phenomenon, respectively. Only $14.4 \%, 18.4 \%$, and $15.4 \%$ of $\mathrm{PM}_{2.5}$ pollution days have no temperature inversion. $\mathrm{PM}_{2.5}$ concentration rises significantly when TI_T is greater than $6^{\circ} \mathrm{C}$ in Harbin and Changchun. However, the relationship between TI_T and $\mathrm{PM}_{2.5}$ in Shenyang is not so significant in pollution days. The TI_D in Shenyang is generally thicker than that of other two cities. Heavy pollution usually occurs when TI_D is bigger than $600 \mathrm{~m}$ in Harbin and Shenyang. Compared to summer, the inversion layer in winter is thicker and has a longer duration. The atmosphere remains static once temperature inversion occurs. In static atmosphere, air pollutants are not easily dispersed vertically and, thus, accumulated near the surface. Additionally, a large temperature difference within a thin inversion layer can also cause high concentrations of $\mathrm{PM}_{2.5}$ in the ground layer.

As can be seen in Fig. 5, the relationship between $\mathrm{RH}$ and $\mathrm{PM}_{2.5}$ in Northeast China is not as significant as other air pollution areas. There is even a negative correlation between $\mathrm{PM}_{2.5}$ and $\mathrm{RH}$. Possible reasons are that rainy and snowy weather accompanied with moist air can deposit the particulate pollutants so that air becomes clear, and when the air pollution is caused by the dust particles, the moisture in the air remains constantly low (Sun et al., 2013).

\section{Quantitative Multiple Regression Analysis between PM2.5 Concentration and Meteorological Factors}

$\mathrm{PM}_{2.5}$ concentration has dropped continuously during the past three years in Northeast China. However, daily $\mathrm{PM}_{2.5}$ levels varied remarkably, rising and falling rapidly with alternating sharp peaks and deep troughs (Wen et al., 2018). In Table 1, the confidence coefficient for meteorological factors above $95 \%$ confidence level ( $\mathrm{p}$-value $<0.05$ ) indicates the factors significantly impact the daily variation of $\mathrm{PM}_{2.5}$ concentration to some extent. Wind speed, HPBL, and temperature inversion are important meteorological factors affecting the $\mathrm{PM}_{2.5}$ pollution in Northeast China. During pollution days, the regression coefficients of wind speed and HPBL are negative values, which show a clear negative influence of wind speed and HPBL on fine particle concentrations. Meanwhile, the values for the coefficients of TI_T and TI_D are positive, which indicates that temperature inversion has a positive impact on the accumulation of $\mathrm{PM}_{2.5}$. A meteorological factor plays the dominant role in affecting $\mathrm{PM}_{2.5}$ pollution when its standardized coefficient
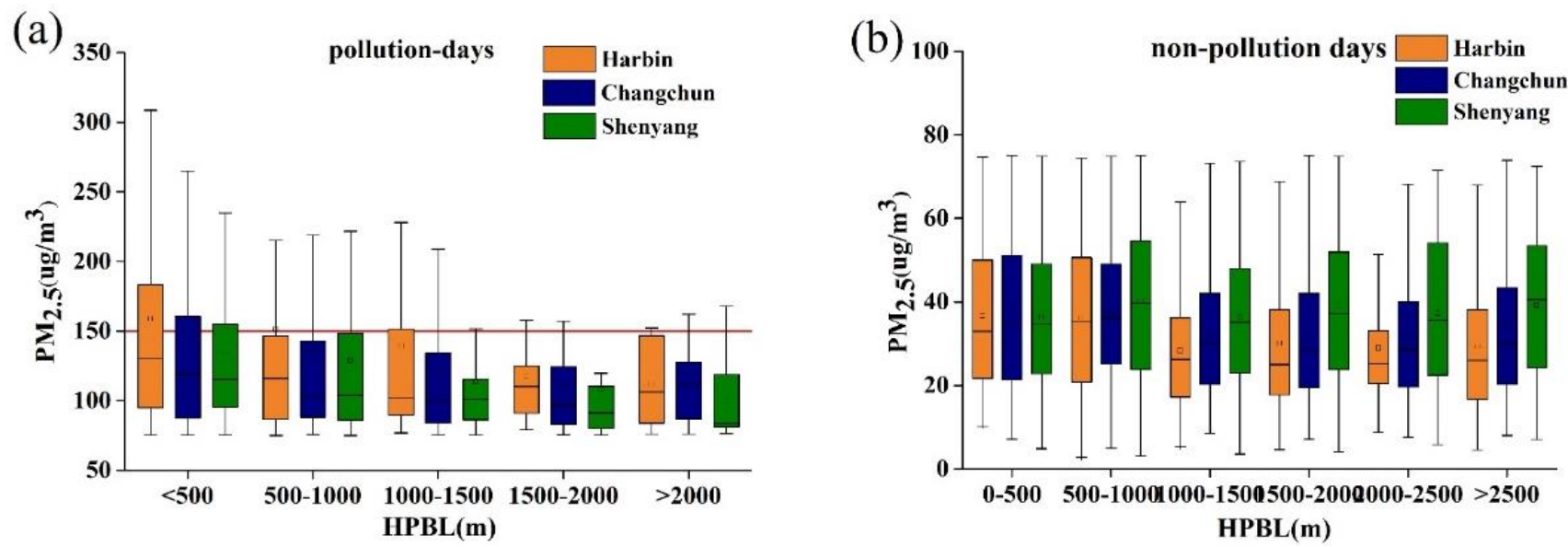

Fig. 3. Correlation between $\mathrm{PM}_{2.5}$ and the height of the planetary boundary layer in Harbin, Changchun, and Shenyang for (a) pollution days $\left(>75 \mu \mathrm{g} \mathrm{m}^{-3}\right)$ and (b) non-pollution days $\left(\leq 75 \mu \mathrm{g} \mathrm{m}^{-3}\right)$. 

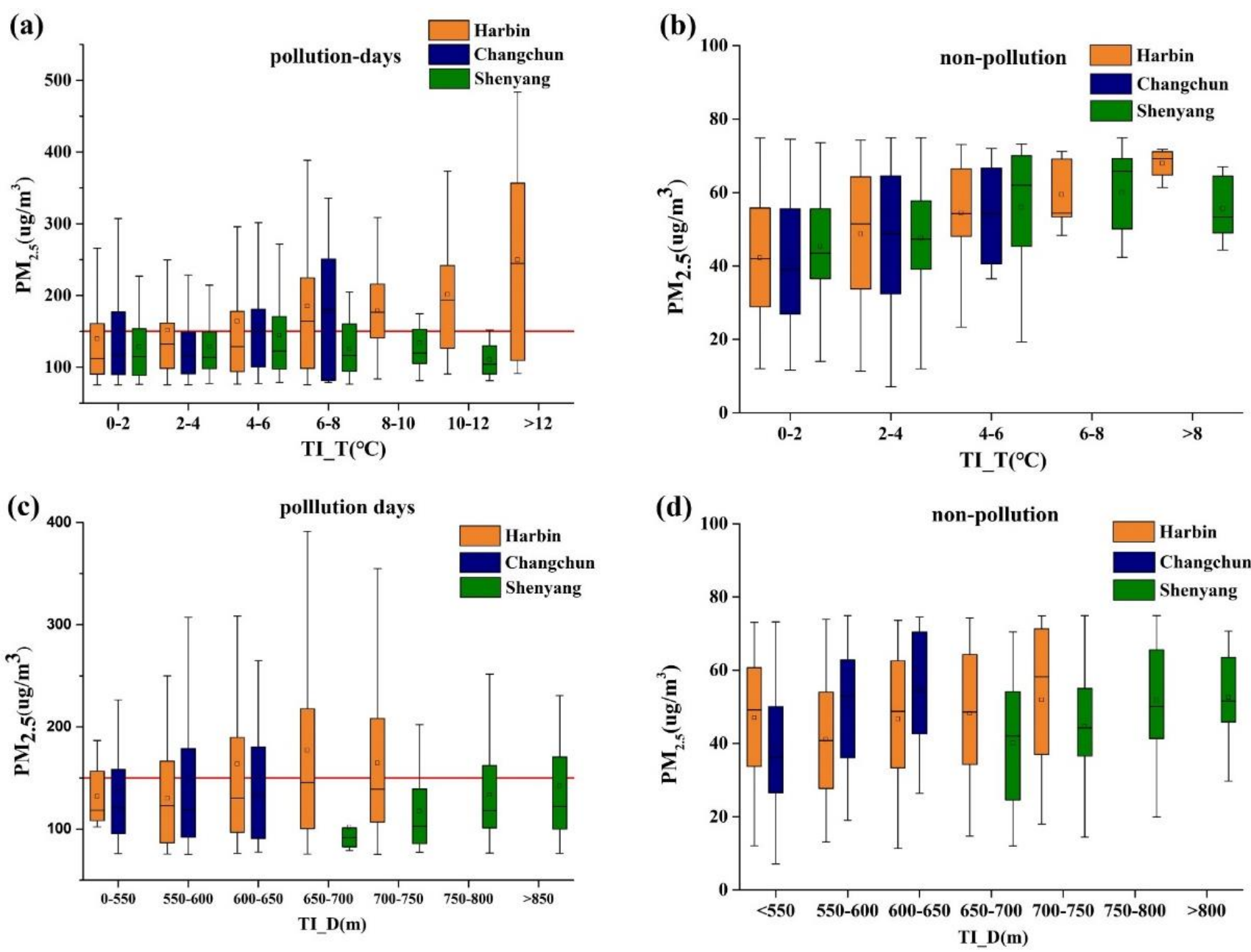

Fig. 4. Statistics of $\mathrm{PM}_{2.5}$ concentrations with temperature inversion. Variation of the $\mathrm{PM}_{2.5}$ concentrations correlated with the temperature difference of the inversion layer (TI_T) during (a) pollution days $\left(>75 \mu \mathrm{g} \mathrm{m}^{-3}\right.$ ) and (b) non-pollution days $\left(\leq 75 \mu \mathrm{g} \mathrm{m}^{-3}\right)$. Variation of the $\mathrm{PM}_{2.5}$ concentrations correlated with the depth of temperature inversion (TI_D) during (c) pollution days $\left(>75 \mu \mathrm{g} \mathrm{m}^{-3}\right)$ and (d) non-pollution days $\left(\leq 75 \mu \mathrm{g} \mathrm{m}^{-3}\right)$.

has the biggest absolute value. By comparing the standardized coefficients of different factors in the regression model, the most important factors are concluded. Wind speed is the key meteorological factor impacting $\mathrm{PM}_{2.5}$ concentrations in Harbin and Shenyang. Meanwhile, HPBL is the key factor in Changchun.

Straw burning and pollutant emission, near-surface temperature inversion, and static wind together with other extreme meteorological conditions contribute to the $\mathrm{PM}_{2.5}$ pollution, especially in autumn and winter. The breeze hinders the dispersion and transport of the atmospheric pollutants released by straw burning. On the contrary, high wind speed is beneficial to the horizontal dilution of the pollutants. On the other hand, the turbulence is strengthened with the increase of wind speed, which is also beneficial to the pollutant dilution and spreading. There are significant differences between the situations with and without the existence of temperature inversion. Temperature inversion decreases the upward movement of the lower atmosphere and causes the pollutants trapped in the lower atmosphere. Frequent atmospheric conditions with temperature inversion in winter can cause the accumulation of atmospheric particles (He et al., 2001; Han et al., 2010). The convection between upper and lower layers decreases, so that the atmospheric pollutants in the near-surface layer can hardly be transported upward. At the same time, the pollutants never stop accumulating, which exacerbates air pollution. The diffusion and transportation of pollutants in the lower atmosphere depends to a large extent on the boundary layer structure. Within the boundary layer, turbulence can fully mix particles and gases. All the three factors have significant influence on the $\mathrm{PM}_{2.5}$ concentrations in Northeast China. As can be seen in the multiple regression result (Table 1), during pollution days, all the three cities have the wind speed as one of the major impact factors. However, different from other two cities, the temperature inversion is not a major impact factor for Changchun. Such result may be caused by the fact that the altitude of Changchun $(236.8 \mathrm{~m})$ is higher than Harbin $(171.7 \mathrm{~m})$ and Shenyang $(41.6 \mathrm{~m})$. And the temperature inversion has the characteristic that it occurs more obviously in the lowland (or valley) area than the highland area.

As can be seen from Table 2, during non-pollution days, 

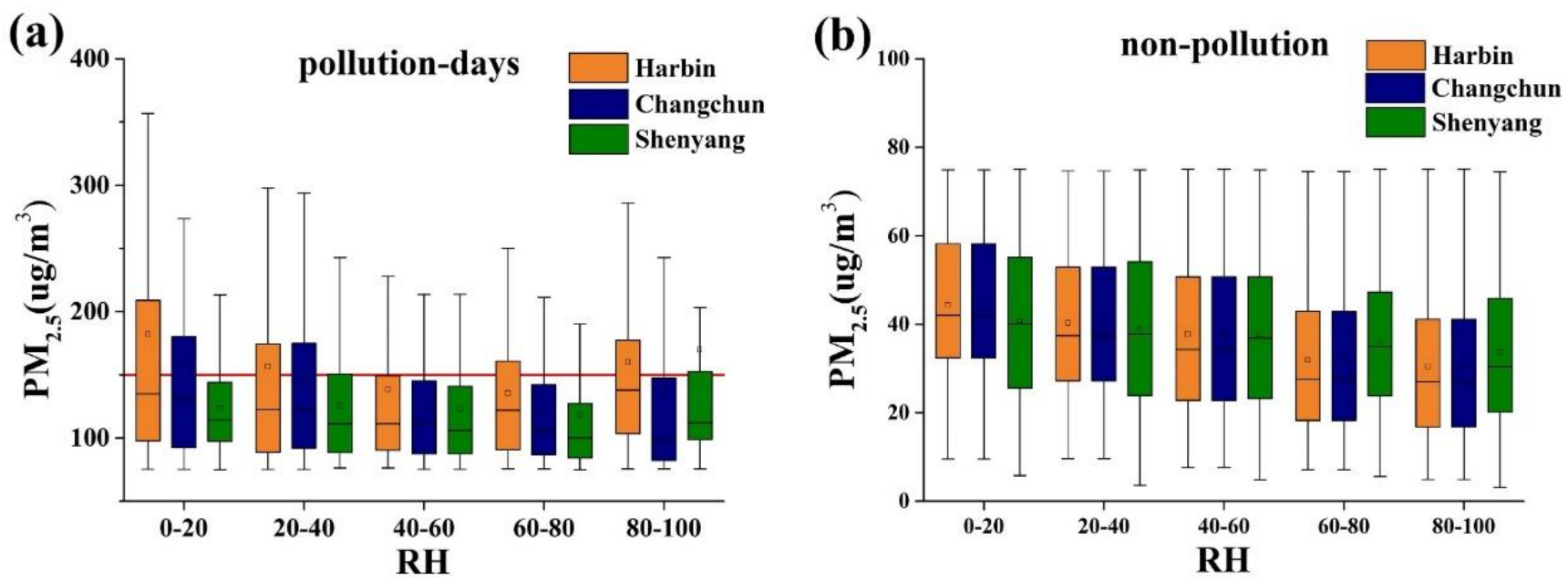

Fig. 5. Variation of the $\mathrm{PM}_{2.5}$ concentrations correlated with different $\mathrm{RH}$ condition during (a) pollution days (> $75 \mu \mathrm{g} \mathrm{m}^{-3}$ ) and (b) non-pollution days $\left(\leq 75 \mu \mathrm{g} \mathrm{m}^{-3}\right)$ in Harbin, Changchun, and Shenyang respectively. The RH is divided into 5 segments (i.e., $0-20,20-40,40-60,60-80$, and 80-100).

Table 1. Regression coefficients, standardized coefficients and p-values of different meteorological factors during pollution days in Northeast China.

\begin{tabular}{lllllll}
\hline City & Evaluating index & Wind speed & HPBL & TI_T & TI_D & RH \\
\hline Harbin & Regression coefficient & -0.237 & -0.084 & 0.110 & 0.026 & -0.042 \\
& Standardized coefficient & $\mathbf{- 0 . 2 5 2}$ & -0.226 & 0.236 & 0.006 & -0.052 \\
& p-value & $\mathbf{8 . 0 3 E - 0 7}$ & $\mathbf{2 . 1 1 E - 0 5}$ & $\mathbf{1 . 2 7 E - 0 6}$ & 0.938 & 0.279 \\
Changchun & Regression coefficient & -0.146 & -0.061 & -0.023 & 0.277 & -0.034 \\
& Standardized coefficient & -0.189 & $\mathbf{- 0 . 1 9 4}$ & -0.037 & 0.024 & -0.071 \\
& p-value & $\mathbf{0 . 0 2 4}$ & $\mathbf{0 . 0 2 2}$ & 0.556 & 0.617 & 0.503 \\
& Regression coefficient & -0.141 & -0.028 & 0.010 & 1.482 & 0.043 \\
Shenyang & Standardized coefficient & $\mathbf{- 0 . 2 4 7}$ & -0.120 & 0.029 & 0.214 & 0.107 \\
& p-value & $\mathbf{6 . 9 6 E - 0 5}$ & 0.06437 & 0.652 & $\mathbf{0 . 0 0 1}$ & 0.088 \\
\hline
\end{tabular}

Table 2. Regression coefficients, standardized coefficients and p-values of meteorological factors during clear days in Northeast China.

\begin{tabular}{lllllll}
\hline City & Evaluating index & Wind speed & HPBL & TI_T & TI_D & RH \\
\hline Harbin & Regression coefficient & 0.103 & -0.098 & 0.082 & 0.294 & 0.025 \\
& Standardized coefficient & 0.084 & $\mathbf{- 0 . 2 4 3}$ & 0.189 & 0.053 & 0.035 \\
& p-value & 0.196 & $\mathbf{0 . 0 0 0 2}$ & $\mathbf{0 . 0 0 4}$ & 0.399 & 0.591 \\
Changchun & Regression coefficient & 0.059 & -0.065 & 0.068 & 1.601 & -0.134 \\
& Standardized coefficient & 0.063 & -0.175 & 0.126 & $\mathbf{0 . 3 1 5}$ & -0.157 \\
& p-value & 0.365 & $\mathbf{0 . 0 1 2}$ & 0.064 & $\mathbf{2 . 6 7 E - 0 5}$ & $\mathbf{0 . 0 3 0}$ \\
Shenyang & Regression coefficient & 0.080 & 0.031 & 0.048 & 1.461 & 0.003 \\
& Standardized coefficient & 0.120 & 0.117 & 0.124 & $\mathbf{0 . 2 3 6}$ & 0.005 \\
& p-value & 0.092 & 0.103 & 0.126 & $\mathbf{0 . 0 0 1}$ & 0.942 \\
\hline
\end{tabular}

HPBL and temperature inversion are important factors affecting $\mathrm{PM}_{2.5}$ in Harbin and Changchun. In Shenyang, TI_D is the only important determinant impacting PM $_{2.5}$ concentration. In summer, the thickened mixing layer improves the dispersion of pollutants in the atmosphere. In winter, frequent and persistent thermal inversions at ground level drive considerable amount of air pollutants to accumulate in the lower layer of the atmosphere (Marcazzan et al., 2001). Although wind speed, HPBL, and TI_T are important factors of $\mathrm{PM}_{2.5}$ concentration, their correlations with $\mathrm{PM}_{2.5}$ concentration during non-pollution days are not significant.

Fig. 6 shows the occurrence of $\mathrm{PM}_{2.5}$ pollution and nonpollution days in different meteorological conditions from 2015 to 2017. The meteorological factors for different cities are selected based on the significance level of $95 \%$ in Table 1. For Harbin, HPBL, WV, and TI_T are major impact factors. $\mathrm{PM}_{2.5}$ pollution usually occurs, with a possibility of $91.6 \%$, when the wind speed is under 20 knots, HPBL is lower than $1500 \mathrm{~m}$ and TI_T is higher than $8^{\circ} \mathrm{C}$. On the contrary, the possibility of occurrence of $\mathrm{PM}_{2.5}$ pollution is 

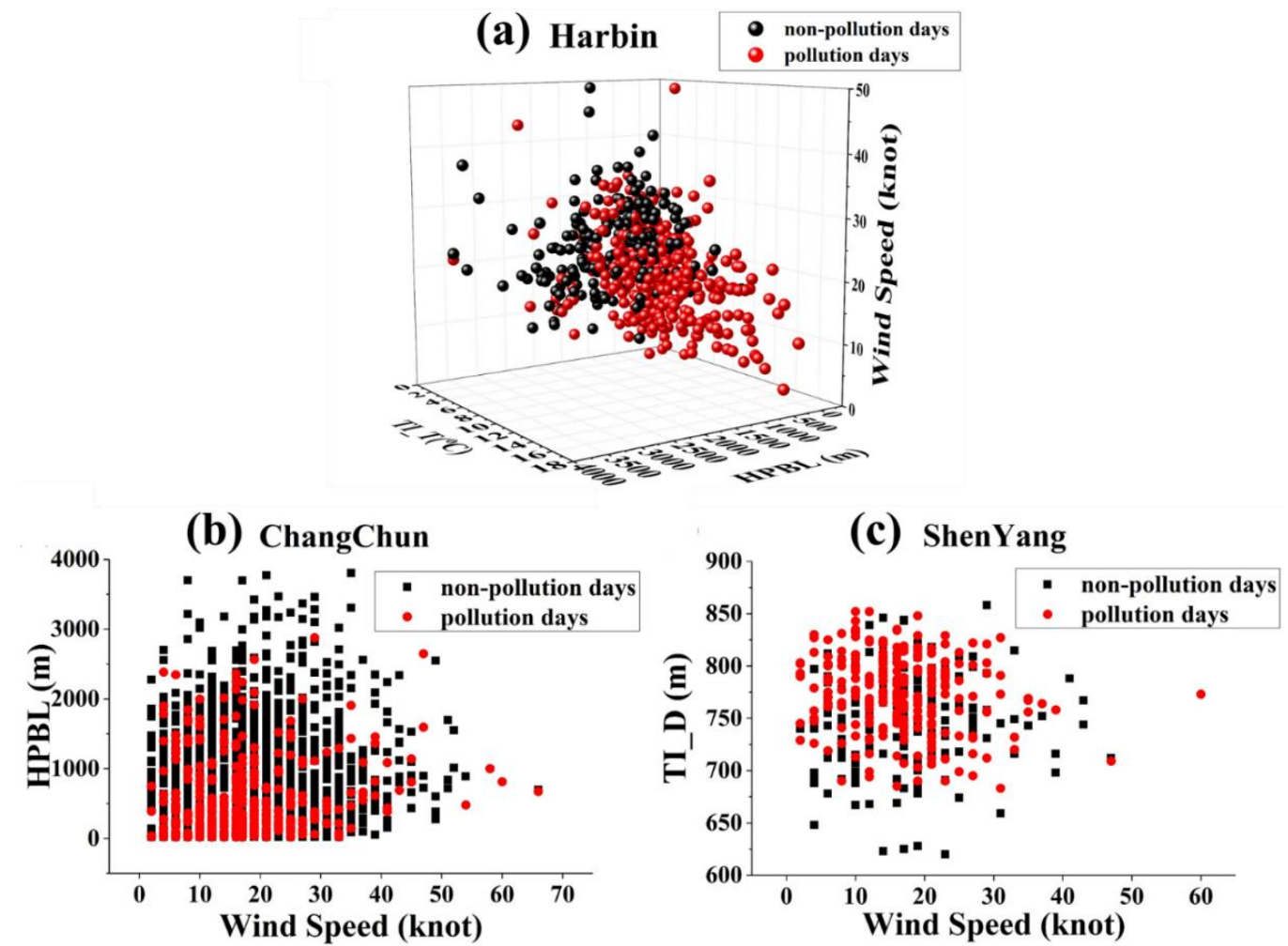

Fig. 6. The occurrence of $\mathrm{PM}_{2.5}$ pollution and non-pollution days in different meteorological conditions from 2015 to 2017 in (a) Harbin, (b) Changchun, and (c) Shenyang.

only $27.2 \%$ for the whole year. For Changchun, $\mathrm{PM}_{2.5}$ pollution is majorly impacted by wind speed and HPBL, the possibility is $61.7 \%$ when the wind speed is under 20 knots and HPBL is lower than $600 \mathrm{~m}$. Meanwhile, the possibility is only $22.7 \%$ for the whole year. As for Shenyang, the possibility of the occurrence of $\mathrm{PM}_{2.5}$ pollution rises from $24.9 \%$ to $70.3 \%$ when the wind speed is under 20 knots, and TI_D is greater than $775 \mathrm{~m}$.

\section{CONCLUSIONS}

To evaluate the effect of meteorological conditions on $\mathrm{PM}_{2.5}$ pollution in Northeast China, we applied a regression method to long-term ground-based $\mathrm{PM}_{2.5}$ data and radiosonde measurements. We found that the wind speed, HPBL, and temperature inversion were the primary factors influencing the fine particulate pollution in this region. Whereas the wind speed exhibited the strongest correlations with the $\mathrm{PM}_{2.5}$ levels in Harbin and Shenyang, the HPBL played the key role in Changchun, with the meteorological data showing significant negative effects from both of these factors on the fine particle concentration. By contrast, the temperature inversion, described using TI_T and TI_D, was positively correlated with the concentration.

In Harbin, the probability of $\mathrm{PM}_{2.5}$ pollution was $91.6 \%$ when the wind speed was less than 20 knots, the HPBL was below $1500 \mathrm{~m}$, and TI_T was greater than $8^{\circ} \mathrm{C}$. In Changchun, the probability was $61.7 \%$ when the wind speed was less than 20 knots and the HPBL was below $600 \mathrm{~m}$. Finally, in Shenyang, the probability was $70.3 \%$ when the wind speed was less than 20 knots and TI_D was more than $775 \mathrm{~m}$. Unlike other typical polluted areas, the variation in the $\mathrm{PM}_{2.5}$ concentration during polluted days in Northeast China little depended on the RH.

In addition to anthropogenic emissions, which necessitate local control strategies, the ambient meteorological conditions play a large role in $\mathrm{PM}_{2.5}$ pollution in Northeast China and must be considered in order to efficiently decrease air pollution in this region. For example, when temperature inversion occurs, reducing coal and petroleum consumption should be contemplated as a potential preventative measure.

Our study provides preliminary results on the major meteorological factors that affect the accumulation and dispersion of $\mathrm{PM}_{2.5}$ pollution. Further studies may examine additional meteorological parameters and expand the observation period. Furthermore, we used the nocturnal HPBL data which is usually dominated by the residual layer, and the relevancy between $\mathrm{PM}_{2.5}$ and HPBL may not be true in nighttime. This issue can also be addressed in the future.

\section{ACKNOWLEDGEMENTS}

This work is supported by the National Key Research and Development Program of China (2017YFC0212302). We would like to thank the Ministry of Environmental Protection of China for providing the $\mathrm{PM}_{2.5}$ observation data (http://106.37.208.233:20035/) used in this study. We highly appreciate the National Oceanic and Atmospheric Administration (NOAA) as well as the Integrated Global Radiosonde Archive (IGRA) for giving us access to the 
historical radiosonde data. We would also like to show great gratitude to the National Center for Atmospheric Research (NCAR), associated with the University Corporation for Atmospheric Research (UCAR), for the generous provision of HPBL data. Without these institutions the experiments could not be conducted.

\section{REFERENCE}

Bao, J.Z., Yang, X.P., Zhao, Z.Y., Wang, Z.K., Yu, C.H. and Li, X.D. (2015). The spatial-temporal characteristics of air pollution in China from 2001-2014. Int. J. Environ. Res. Public Health 12: 15875-15887. https://doi.org/10. 3390/ijerph121215029

Chaloulakou, A., Kassomenos, P., Spyrellis, N., Demokritou, P. and Koutrakis, P. (2003). Measurements of $\mathrm{PM}_{10}$ and $\mathrm{PM}_{2.5}$ particle concentrations in Athens, Greece. Atmos. Environ. 37: 649-660. https://doi.org/10.1016/S13522310(02)00898-1

Chen, T., Guo, J., Li, Z., Zhao, C., Liu, H., Cribb, M., Wang, F. and He, J. (2016). A CloudSat perspective on the cloud climatology and its association with aerosol perturbations in the vertical over Eastern China. J. Atmos. Sci. 73: 3599-3616. https://doi.org/10.1175/JAS-D-15-0309.1

Chen, W.W., Tong, D., Zhang, S.C., Dan, M., Zhang, X.L. and Zhao, H.M. (2015). Temporal variability of atmospheric particulate matter and chemical composition during a growing season at an agricultural site in northeastern China. J. Environ. Sci. 38: 133-141. https://doi.org/10.1016/j.jes.2015.05.023

Chen, W.W., Tong, D.Q., Dan, M., Zhang, S.C., Zhang, X.L. and Pan, Y.P. (2017). Typical atmospheric haze during crop harvest season in northeastern China: A case in the Changchun region. J. Environ. Sci. 54: 101-113. https://doi.org/10.1016/j.jes.2016.03.031

Chen, Z., Xie, X., Cai, J., Chen, D., Gao, B., He, B., Cheng, N. and $\mathrm{Xu}, \mathrm{B}$. (2018). Understanding meteorological influences on $\mathrm{PM}_{2.5}$ concentrations across China: A temporal and spatial perspective. Atmos. Chem. Phys. 18: 5343-5358. https://doi.org/10.5194/acp-18-5343-2018

Cheng, S.Q. and Lam, K.C. (1998). An analysis of winds affecting air pollution concentrations in Hong Kong. Atmos. Environ. 32: 2559-2567. https://doi.org/10.1016/ S1352-2310(97)00514-1

Dickerson, R.R., Li, C., Li, Z., Marufu, L.T., Stehr, J.W., McClure, B., Krotkov, N., Chen, H., Wang, P., Xia, X., Ban, X., Gong, F., Yuan, J. and Yang, J. (2007). Aircraft observations of dust and pollutants over northeast China: Insight into the meteorological mechanisms of transport. J. Geophys. Res. 112: D24S90. https://doi.org/10.1029/20 07JD008999

Durre, I., Vose, R.S. and Wuertz, D.B. (2006). Overview of the integrated global radiosonde archive. J. Clim. 19: 5368. https://doi.org/10.1175/JCLI3594.1

Fan, J., Wang, Y., Rosenfeld, D. and Liu, X. (2016). Review of aerosol-cloud interactions: Mechanisms, significance, and challenges. J. Atmos. Sci. 73: 4221-4252. https://doi. org/10.1175/JAS-D-16-0037.1

Fang, C.S., Zhang, Z.D., Jin, M.Y., Zou, P.C. and Wang, J.
(2017). Pollution characteristics of $\mathrm{PM}_{2.5}$ aerosol during haze periods in Changchun, China. Aerosol Air Qual. Res. 17: 888-895. https://doi.org/10.4209/aaqr.2016.09.0407

Fang, F.M., Wang, Q.C., Liu, R.H., Ma, Z.W. and Hao, Q.J. (2001). Atmospheric particulate mercury in Changchun City, China. Atmos. Environ. 35: 4265-4272. https://doi.org/10.1016/S1352-2310(01)00203-5

Garratt, J.R. (1994). The atmospheric boundary layer. Earth Sci. Rev. 37: 89-134. https://doi.org/10.1016/0012-8252 (94)90026-4

Gu, X.F., Bao, F.W., Cheng, T.H., Chen, H., Wang, Y. and Guo, H. (2018). The impacts of regional transport and meteorological factors on aerosol optical depth over Beijing, 1980-2014. Sci. Rep. 8: 5113. https://doi.org/10.1 038/s41598-018-22803-X

Guan, Q.Y., Li, F.C., Yang, L.Q., Zhao, R., Yang, Y.Y. and Luo, H.P. (2018). Spatial-temporal variations and mineral dust fractions in particulate matter mass concentrations in an urban area of northwestern China. J. Environ. Manage. 222: 95-103. https://doi.org/10.1016/j.jenvman.2018.05. 064

Guo, J., Deng, M., Lee, S.S., Wang, F., Li, Z., Zhai, P., Liu, H., Lv, W., Yao, W. and Li, X. (2016). Delaying precipitation and lightning by air pollution over the Pearl River Delta. Part I: Observational analyses. J. Geophys. Res. 121: 6472-6488. https://doi.org/10.1002/2015JD023257

Guo, J., Su, T., Chen, D., Wang, J., Li, Z., Lv, Y., Guo, X., Liu, H., Cribb, M. and Zhai, P. (2019). Declining summertime local-scale precipitation frequency over China and the United States, 1981-2012: The disparate roles of aerosols. Geophys. Res. Lett. 46: 13281-13289. https://doi.org/10.1029/2019GL085442

Han, B., Kong, S.F., Bai, Z.P., Du, G., Bi, T., Li, X., Shi, G.L. and Hu, Y. (2010). Characterization of elemental species in $\mathrm{PM}_{2.5}$ samples collected in four cities of Northeast China. Water Air Soil Pollut. 209: 15-28. https://doi.org/10.1007/s11270-009-0176-8

He, K.B., Yang, F.M., Ma, Y.L., Zhang, Q., Yao, X.H., Chan, C.K., Cadle, S., Chan, T. and Mulawa, P. (2001). The characteristics of $\mathrm{PM}_{2.5}$ in Beijing, China. Atmos. Environ. 35: 4959-4970. https://doi.org/10.1016/S13522310(01)00301-6

Heal, M.R., Kumar, P. and Harrison, R.M. (2012). Particles, air quality, policy and health. Chem. Soc. Rev. 41: 66066630. https://doi.org/10.1039/c2cs35076a

Hien, P.D., Bac, V.T., Tham, H.C., Nhan, D.D. and Vinh, L.D. (2002). Influence of meteorological conditions on $\mathrm{PM}_{2.5}$ and $\mathrm{PM}_{2.5-10}$ concentrations during the monsoon season in Hanoi, Vietnam. Atmos. Environ. 36: 34733484. https://doi.org/10.1016/S1352-2310(02)00295-9

Jung, K.H., Patel, M.M., Moors, K., Kinney, P.L., Chillrud, S.N., Whyatt, R., Hoepner, L., Garfinkel, R., Yan, B. and Ross, J. (2010). Effects of heating season on residential indoor and outdoor polycyclic aromatic hydrocarbons, black carbon, and particulate matter in an urban birth cohort. Atmos. Environ. 44: 4545-4552. https://doi.org/1 0.1016/j.atmosenv.2010.08.024

Kan, H.D., Chen, R.J. and Tong, S.L. (2012). Ambient air pollution, climate change, and population health in China. 
Environ. Int. 42: 10-19. https://doi.org/10.1016/j.envint.2 011.03.003

Li, L., Tan, Q., Zhang, Y., Feng, M., Qu, Y., An, J. and Liu, X. (2017a). Characteristics and source apportionment of $\mathrm{PM}_{2.5}$ during persistent extreme haze events in Chengdu, southwest China. Environ. Pollut. 230: 718-729. https://doi.org/10.1016/j.envpol.2017.07.029

Li, Z., Guo, J., Ding, A., Liao, H., Liu, J., Sun, Y., Wang, T., Xue, H., Zhang, H. and Zhu, B. (2017b). Aerosol and boundary-layer interactions and impact on air quality. Natl. Sci. Rev. 4: 810-833. https://doi.org/10.1093/nsr/n wx117

Li, Z., Wang, Y., Guo, J., Zhao, C., Cribb, M.C., Dong, X., Fan, J., Gong, D., Huang, J., Jiang, M., Jiang, Y., Lee, S.S., Li, H., Li, J., Liu, J., Qian, Y., Rosenfeld, D., Shan, S., Sun, Y., Wang, H., Xin, J., Yan, X., Yang, X., Yang, X.Q., Zhang, F. and Zheng, Y. (2019). East Asian Study of Tropospheric Aerosols and their Impact on Regional Clouds, Precipitation, and Climate (EAST-AIRCPC). $J$. Geophys. Res. 124: 13026-13054. https://doi.org/10.102 9/2019JD030758

Liang, X., Zou, T., Guo, B., Li, S., Zhang, H.Z., Zhang, S.Y., Huang, H. and Chen, S.X. (2015). Assessing Beijing's $\mathrm{PM}_{2.5}$ pollution: Severity, weather impact, APEC and winter heating. Proc. R. Soc. London, Ser. A 471: 20150257. https://doi.org/10.1098/rspa.2015.0257

Liu, L., Guo, J., Miao, Y., Liu, L., Li, J., Chen, D., He, J. and Cui, C. (2018). Elucidating the relationship between aerosol concentration and summertime boundary layer structure in central China. Environ. Pollut. 241: 646-653. https://doi.org/10.1016/j.envpol.2018.06.008

Lohmann, U. and Feichter, J. (2001). Can the direct and semi-direct aerosol effect compete with the indirect effect on a global scale? Geophys. Res. Lett. 28: 159-161. https://doi.org/10.1029/2000GL012051

Lou, M., Guo, J., Wang, L., Xu, H., Chen, D., Miao, Y., Lv, Y., Li, Y., Guo, X., Ma, S. and Li, J. (2019). On the relationship between aerosol and boundary layer height in summer in China under different thermodynamic conditions. Earth Space Sci. 6: 887-901. https://doi.org/ 10.1029/2019EA000620

Ma, Q.X., Wu, Y.F., Zhang, D.Z., Wang, X.J., Xia, Y.J., Liu, X.Y., Tian, P., Han, Z.W., Xia, X.G., Wang, Y. and Zhang, R.J. (2017). Roles of regional transport and heterogeneous reactions in the $\mathrm{PM}_{2.5}$ increase during winter haze episodes in Beijing. Sci. Total Environ. 599: 246-253. https://doi.org/10.1016/j.scitotenv.2017.04.193

Marcazzan, G.M., Vaccaro, S., Valli, G. and Vecchi, R. (2001). Characterisation of $\mathrm{PM}_{10}$ and $\mathrm{PM}_{2.5}$ particulate matter in the ambient air of Milan (Italy). Atmos. Environ. 35: 4639-4650. https://doi.org/10.1016/S1352-2310(01) 00124-8

Miao, Y., Guo, J., Liu, S., Liu, H., Zhang, G., Yan, Y. and He, J. (2017). Relay transport of aerosols to BeijingTianjin-Hebei region by multi-scale atmospheric circulations. Atmos. Environ. 165: 35-45. https://doi.org/ 10.1016/j.atmosenv.2017.06.032

Newman, T.B. and Browner, W.S. (1991). In defense of standardized regression coefficients. Epidemiology 2:
383-386. https://doi.org/10.1097/00001648-19910900000014

Petäjä, T., Järvi, L., Kerminen, V.m., Ding, A., Sun, J., Nie, W., Kujansuu, J., Virkkula, A., Yang, X., Fu, C., Zilitinkevich, S. and Kulmala, M. (2016). Enhanced air pollution via aerosol-boundary layer feedback in China. Sci. Rep. 6: 18998. https://doi.org/10.1038/srep18998

Rosenfeld, D., Sherwood, S., Wood, R. and Donner, L. (2014). Climate effects of aerosol-cloud interactions. Science 343: 379. https://doi.org/10.1126/science. 1247490

Ruellan, S. and Cachier, H. (2001). Characterisation of fresh particulate vehicular exhausts near a Paris high flow road. Atmos. Environ. 35: 453-468. https://doi.org/10.1016/S1 352-2310(00)00110-2

Segura, S., Estellés, V., Esteve, A.R., Utrillas, M.P. and Martínez-Lozano, J.A. (2013). Analysis of a severe pollution episode in Valencia (Spain) and its effect on ground level particulate matter. J. Aerosol Sci. 56: 41-52. https://doi.org/10.1016/j.jaerosci.2012.06.007

Seinfeld, J.H., Pandis, S.N. and Noone, K. (1998). Atmospheric chemistry and physics: From air pollution to climate change. Wiley, New York.

Sun, Y.L., Wang, Z.F., Fu, P.Q., Jiang, Q., Yang, T., Li, J. and Ge, X.L. (2013). The impact of relative humidity on aerosol composition and evolution processes during wintertime in Beijing, China. Atmos. Environ. 77: 927934. https://doi.org/10.1016/j.atmosenv.2013.06.019

Tian, M., Wang, H.B., Chen, Y., Zhang, L.M., Shi, G.M., Liu, Y., Yu, J.Y., Zhai, C.Z., Wang, J. and Yang, F.M. (2017). Highly time-resolved characterization of watersoluble inorganic ions in $\mathrm{PM}_{2.5}$ in a humid and acidic mega city in Sichuan Basin, China. Sci. Total Environ. 580: 224-234. https://doi.org/10.1016/j.scitotenv.2016.1 2.048

Twomey, S. (1977). The influence of pollution on the shortwave albedo of clouds. J. Atmos. Sci. 34: 11491152. https://doi.org/10.1175/1520-0469(1977)034\%3C1 149:TIOPOT\%3E2.0.CO;2

Wang, H., Xu, J., Zhang, M., Yang, Y., Shen, X., Wang, Y., Chen, D. and Guo, J. (2014a). A study of the meteorological causes of a prolonged and severe haze episode in January 2013 over central-eastern China. Atmos. Environ. 98: 146157. https://doi.org/10.1016/j.atmosenv.2014.08.053

Wang, J. and Christopher, S.A. (2003). Intercomparison between satellite-derived aerosol optical thickness and $\mathrm{PM}_{2.5}$ mass: Implications for air quality studies. Geophys. Res. Lett. 30: 267-283. https://doi.org/10.1029/2003GL0 18174

Wang, Y.G., Ying, Q., Hu, J.L. and Zhang, H.L. (2014b). Spatial and temporal variations of six criteria air pollutants in 31 provincial capital cities in China during 2013-2014. Environ. Int. 73: 413-422. https://doi.org/10. 1016/j.envint.2014.08.016

Wen, X., Zhang, P.Y. and Liu, D.Q. (2018). Spatiotemporal variations and influencing factors analysis of $\mathrm{PM}_{2.5}$ concentrations in Jilin Province, Northeast China. Chin. Geog. Sci. 28: 810-822. https://doi.org/10.1007/s11769018-0992-0

Xu, T., Song, Y., Liu, M., Cai, X., Zhang, H., Guo, J. and 
Zhu, T. (2019). Temperature inversions in severe polluted days derived from radiosonde data in North China from 2011 to 2016. Sci. Total Environ. 647: 1011-1020. https://doi.org/10.1016/j.scitotenv.2018.08.088

Xu, Z., Yu, D., Jing, L. and Xu, X. (2000). Air pollution and daily mortality in Shenyang, China. Arch. Environ. Health 55: 115-120. https://doi.org/10.1080/00039890009603397

Yang, X., Zhao, C., Guo, J. and Wang, Y. (2016). Intensification of aerosol pollution associated with its feedback with surface solar radiation and winds in Beijing. J. Geophys. Res. 121: 4093-4099. https://doi.org/ 10.1002/2015jd024645

Yao, L., Lu, N. and Jiang, S. (2012). Artificial Neural Network (ANN) for multi-source $\mathrm{PM}_{2.5}$ estimation using surface, MODIS, and meteorological data. 2012 International Conference on Biomedical Engineering and Biotechnology, Macao, 2012, pp. 1228-1231.

You, W., Zang, Z.L., Pan, X.B., Zhang, L.F. and Chen, D. (2015). Estimating $\mathrm{PM}_{2.5}$ in Xi'an, China using aerosol optical depth: A comparison between the MODIS and MISR retrieval models. Sci. Total Environ. 505: 11561165. https://doi.org/10.1016/j.scitotenv.2014.11.024

Zang, Z.L., Wang, W.Q., You, W., Li, Y., Ye, F. and Wang, C.M. (2017). Estimating ground-level $\mathrm{PM}_{2.5}$ concentrations in Beijing, China using aerosol optical depth and parameters of the temperature inversion layer. Sci. Total
Environ. 575: 1219-1227. https://doi.org/10.1016/j.scitot env.2016.09.186

Zhang, G., Li, J., Li, X.D., Xu, Y., Guo, L.L., Tang, J.H., Lee, C.S.L., Liu, X.A. and Chen, Y.J. (2010). Impact of anthropogenic emissions and open biomass burning on regional carbonaceous aerosols in South China. Environ. Pollut. 158: 3392-3400. https://doi.org/10.1016/j.envpol. 2010.07.036

Zhang, P.F., Dong, G.H., Sun, B.J., Zhang, L.W., Chen, X., Ma, N.N., Yu, F., Guo, H.M., Huang, H., Lee, Y.L., Tang, N.J. and Chen, J. (2011). Long-term exposure to ambient air pollution and mortality due to cardiovascular disease and cerebrovascular disease in Shenyang, China. PLoS One 6: e20827. https://doi.org/10.1371/journal.pone.002 0827

Zhang, Q., Quan, J.N., Tie, X.X., Li, X., Liu, Q., Gao, Y. and Zhao, D.L. (2015). Effects of meteorology and secondary particle formation on visibility during heavy haze events in Beijing, China. Sci. Total Environ. 502: 578-584. https://doi.org/10.1016/j.scitotenv.2014.09.079

Received for review, October 24, 2019

Revised, February 19, 2020 Accepted, February 21, 2020 